\title{
Psychological Burnout of Women Working and Housewives at the Menopausal Stage in Amman City / Jordan
}

\author{
Entisar Yousef Smadi ${ }^{1}$ \\ ${ }^{1}$ World Islamic Science \& Education University W.I.S.E., Amman, Jordan \\ Correspondence: Entisar Yousef Smadi. E-mail: entisarsmadi@yahoo.com
}

Received: December 12, 2018

Accepted: December 23, 2018

Online Published: January 30, 2019

doi:10.5539/ass.v15n2p124

URL: https://doi.org/10.5539/ass.v15n2p124

\begin{abstract}
This study aimed to identify the levels of psychological burnout in a sample of working women and housewives at menopausal Stage. To achieve the objectives of the study, a scale of psychological burnout was built, which consists of 20 paragraphs, the study sample was obtained in cooperation with Raihanat Al-osrah Association in Amman, through the announcement of the study, a sample of 50 working women and 50 housewives was selected and applied. the psychological scale, the members of the study sample within the age range of 45-55, The results of statistical analysis " $\mathrm{T}$-Test" showed that there were statistically significant differences in the psychological burnout of housewives was higher than working women, which indicates the positive effect of work in the lives of women, and the risk factors of psychological burnout is related to the physical dimension, and this corresponds to the nature of the menopause stage which is the age of the sample study. The study recommended to provide psychological counseling services for women in general, provide health and psychological care services for women in menopause, and the threat of community programs aimed to supporting and empowering Housewives.
\end{abstract}

Keywords: psychological burnout, working women, housewives, menopause, psychological counseling

\section{Introduction}

During the mid-1970s burnout was introduced by Herbert Freudenberger. Burnout is defined as long-term exposure to chronic job stress resulting in emotional exhaustion. In the research conducted in the years 1998 and 1999 , the focus was mainly on the health factor among women. Various surveys were conducted to find out the vital stress factors and job burnout factors, some researchers emphasized that organizational climate had a major impact on the increased job burnout rate, the main focus was to find out which factors affect the mental health of the female (Gardazi et al., 2016).

Cross-sectional researches have focused on burnout and some health problems: such as sleeping disorders, depression, obesity and muscle pain. However, well-conducted prospective studies are more appropriate for investigating the possible consequences of this syndrome, because these types of studies enable the identification of the temporal relationship between the exposure burnout syndrome and the outcome (Salvagion et al., 2017).

Women of the early centuries were mostly confined to their kitchens and those who were employed to work in factories, farms or shop works. Very few women had the access to higher education and they were forced to be at the mercy of their fathers or husbands' attitudes towards women and work. The fast-developing knowledge economy has given place for several women to be enlightened by higher education. Education has not only empowered them, but also has given them robust careers. With brain power being the requisite skill in this knowledge era, rather than endurance or physical strength, the women workers seem to flood into every industry on par with men. But this has indeed become a tough challenge for women as they must perform a lot of duties in the home and office as well. As working women get married, they have additional responsibilities and when they become mothers, they have to manage the primary care of children and extended family and are thus, under greater pressure to continue on a career path. Working mothers of today fulfill family responsibilities and try to remain fully involved in their careers coping up with the competing demands of their multiple roles. The caring responsibilities that working mothers have laid a heavy stress on them when it is combined with their professional duties (Delina \& Prabhakara Raya, 2013).

Women's roles have changed like: Marriage at a later age and at lower rates, having fewer children, and working more outside of the household. "Career women" are the new normal and housewife role has gone out of fashion 
(Okulcz-kozaryn \& Valente, 2017).

One of the main factors contributing to the psychological situation of women are some of the stations that pass through, including menopause, and the impact this phase has on the lives of women in general. Menopause is described as a period of psychological difficulties that changes the lifestyle of women in multiple ways. Menopausal women require more information about their physical and psycho social needs. Empowerment during the menopause can contribute to improving the perception of this stage and the importance of self-care. It is essential to increase women's awareness and adaptation to menopause, using empowerment programs (Yazdkhasti et al., 2015).

Ageing is an important period of all people not only the biological changes that occur, but also It includes psychological and social changes, aging women often find themselves either ignored, pitied, or feared, which is why most women are very concerned with the ageing factor. The effect of ageing is seen more in middle age women because they are neither fully old nor are they young. They are still compromising with the fact that "age" is slipping out of their hands. Middle age is a phase of transition from a young age to old age, finally accepting age is quite stressful for all (Smadi, 2017).

In Jordan women are a major component of Jordanian society positive developments reflected on the status of women such as reducing the proportion of illiteracy among women, and improvement in the status of healthy women, and an increase in the number of women who have reached positions of leadership in power legislative, executive and judicial. According to official statistics from the Department of Statistics, The female rate was $48.5 \%$ compared to $51.5 \%$ for males in 2013. Despite the high percentage of females in Jordanian society, the indicators for working women, where the percentage of women's participation in the Jordanian labor market is low (Assaf, 2015).

The idea of this research was based on the need to study issues related to women in general and to focus on menopause, this is because menopause has undergone significant changes in women at the health, psychological and social levels. In addition to the importance of awareness of the level of psychological burnout of working women and housewives, studying psychological burnout highlights on the level of efficiency and mental health, and because issues relating to housewives are not clear to most people, the researcher found it useful to address the issues and problems experienced by housewives.

\subsection{Problem of This Study}

The problem of this study is centered on the following issues:

- Housewives do a lot of housework and lack of community attention to these works and suffering of routine burdens, interference of family and professional burdens of working women and suffering women from the symptoms of menopause and they haven't supported from family or society.

- The state of psychological burnout is a state of stress and fatigue coupled with psychological pressure and lead to a decrease in performance in quantity and quality as the burnout situation leads to a low level of motivation.

- Menopause is an important stage in women's lives, leading to physiological changes associated with the hormonal system changes that cause negative psychological and social effects.

\subsection{The Importance of the Study}

The importance of this study is that it sheds light on the important topic of women is psychological burnout, and its relationship to the multiplicity of roles played by women, In addition, the study sample of women in the menopause stage and the consequent of this stage of psychological stress associated with the physical changes associated with it, the study also dealt with the burnout between working women and housewives in order to identify the psychological impact related to work, whether job or domestic work, the study also dealt with the burnout between working women and housewives in order to identify the psychological impact related to the job or work at house.

\subsection{Study Questions}

1-What are the risk factors of psychological burnout on a sample of women at menopause in Amman?

2-What is the degree of psychological burnout on a sample of working women and housewives in Amman?

3-What is the difference between the level of psychological burnout on a sample of working women and Housewives in Amman?

The study tool was prepared to answer the study questions, it is a scale for measuring the level of psychological burnout. 


\subsection{Tool}

To design the study tool, the researcher conducted a review of some previous studies and theoretical literature, which dealt with the subject of psychological burnout, taking into account that the paragraphs are appropriate for the age of menopause for women.

The scale was designed from twenty paragraphs measuring the state of psychological burnout, only twenty points were taken into consideration for the sample, so that the response was accurate and objective, and also to avoid the possibility of boredom among the respondents, also the scale has different sections that measure all cases women faced.

When the scale was built, it was presented to a group of academics, taking into account their suggestions to modify some of the paragraphs until the scale appeared in its final form.

A scale was designed to identify levels of psychological burnout, it consisted of twenty paragraphs, each paragraph is measured from four levels, number 1 indicate a very low degree, number 2 a few degrees, number 3 Medium degree, number 4 Great degree, and number 5 is Very large degree.

\subsection{Sample of Study}

The study sample was selected in cooperation with the Raihanat Al-osrah Association in Amman. It was announced that the researcher wanted to conduct research about the psychological situation of women, and when women progress to participate in the study, the sample of the study was selected among women aged 45-55, a stage of menopause, the total of sample number is 100 , working women was 50 and housewives was 50 .

The sample responses are calculated by the following equation:

$$
\text { Upper limit }- \text { minimum }=5-1=1.33
$$

\section{Levels 3}

The five-point Likert ladder is used. Therefore, the paragraphs that obtain an arithmetic average between (1-2.33) indicate a low level. (2.34- 3.66) indicates an average level. (3.67-5) indicates a high level.

\subsection{Methodology of Research in This Study}

The descriptive approach was used to answer the study questions and to reach the appropriate conclusions and recommendations.

\subsection{Keywords Definitions}

Psychological burnout: It is the stressful psychological state that leads to the inability continue and finish the tasks efficiently, and works to reduce motivation, which negatively affects the quality of work provided, the degree of psychological burnout is measured in this study to the extent obtained on the scale of psychological burnout.

Working women: women who work in occupations and jobs within the public sector or the private sector, working women in this study are women who have been appling the psychological burnout Scale.

Housewives: women who do not have any job occupational, and do housework: cleaning, cooking and taking care of his garden, in this study, housewives were the ones who applied the scale of psychological burnout.

Menopause: A stage in which women stop their menstrual cycle, which leads to the cessation of fertility, the menopause phase is between 45 and 55 years old, this phase is accompanied by psychological and physical changes, in this study, the menopause stage is the stage of the women who formed the study sample.

Psychological counseling: It is specialized psychological services provided by counselor who is a specialist in psychological guidance, counseling services are usually offered at the preventive, structural and therapeutic levels, the counseling services are directed to many individuals and deal with all ages and various issues.

\section{Literature}

Review here some studies of literature that dealt with topics like the dimension of current study:

Lebert-Charron et al. (2018) They pointed out that maternity is a special condition in women's lives, including substantial and long-lasting mental, social, and physical charge, the parenting experience may also be a potentially stressful and overwhelming task, this study aim to evaluate of psychological factors associated with the maternal burnout syndrome in a French community-based population in order to contribute to better realize the notion of parental burnout. The study sample was 304 French mothers, Women responded to a questionnaire that showed demographic and social information about them, Women also responded to the following criteria: 
Stress Scale, the Maslach Burnout Inventory adapted for parents, the Hospital Anxiety and Depression Scale, Statistical analysis show scores on the parental version were strongly and positively associated with depressive and anxiety symptoms, as well as with perceived stress related to parenting and parenting stress level, task-oriented coping style in parenthood was strongly and positively associated with fulfillment, some demographically shape was found to be negatively associated with maternal burnout: being employed, working full time and being a mother living without a partner.

Ahmad \& Khan (2018) conducted research about: Quality of Life Among Married Working Women and Housewives. The sample of the study was 80 married women participants age ranging from 25-40 years, 40 were Married working women and 40 housewives in Bijnor, statistical analysis showed that there was no difference between married working women and housewives on physical health, whereas both the group differs in psychological married working women are generally more educated and exposed to professional interpersonal relationship. The housewives remain at home and do household work, although she indirectly contributed to the overall output of the family.

Dibaji et al. (2017) conducts research aim to measure stress in housewives and working women, depression and mental and emotional home demands, the sample of the study is 94 working women and 94 housewives in Isfahan, the tool of this study stress questionnaire, Beck Depression II and home demands questionnaire. Results show that working women more depression and quantitative and mental home demands, but no differences between working women and housewives in terms of stress and emotional home demands, it seems that the stress of work and family role, especially time pressure means that despite the positive role of work in working women, they were psychologically vulnerable because of the multiplicity of tasks. The results focus on the culture in terms of the role of men in the house, especially when the women are working.

Choudhary \& Ahmad (2017) finishing research in India, this study purpose to check the levels of psychological well-being among the housewives and working women of Mithila region, North Bihar. The sample consisted of 120 women comprising housewives $(n=60)$ and working women $(n=60)$ from different organizations where women are dependent on their husbands, The tool is questionnaires using Psychological Well-being scale, results indicated that menopause housewives have low levels of psychological well-being in comparison to menopause working women and both of menopause housewives and menopause working women need to have social and emotional support from their respective social and family institutions as reported by them.

"Causes of Stress and Burnout among Working Mothers in Pakistan," it is the title of study by Gardazi et al. (2016) this study examined the reasons of psychological burnout among working mothers in Pakistan. This qualitative study interviewed 12 Pakistani working mothers, through phenomenological method several themes and sub themes emerged which provided a description of the experience. Four themes work health factor, work overload, work environment, work family conflict and six sub themes emerged from the data. This work explores the reasons of the burnout among working mothers and provides recommendations for further examination. Interview results show that participants are going through the same level of stress at the certain stage.

A study by Kerman (2016) aim to evaluate the stress level among the working women and housewives and its management through Progressive muscle relaxation (PMRT) and Mindful breathing, the sample of the study was 100 women 50 working and 50 housewives. The women responded to the valid and reliable instrument, the researcher was used pre and post-test design, statically analysis was done, Results reveal that the stress level was high among the working women in comparison to housewives, Intervention sessions of Progressive muscle relaxation technique and mindfulness breathing were provided to the experimental group of 25 working, after the intervention post-test appears determined the significant decline in the stress level of Experimental group of employed women and no decline in the control group. The stress level was reduced from moderate to low level of stress.

Study by Molodi et al. (2015) aim to identify the relationship between communication skills and the level of burnout and commitment in the marital relationship. The which applied was: Communication Skills Questionnaire, Couple Burnout Measure and "Dimensions of Commitment Inventory. The study sample included 200 women who are workers and housewives. Researchers used Pearson correlation coefficient, regression analysis (multiple and synchronous model) and t-test for data analysis, the results showed statistically significant differences in the study variables, the study recommended that the psychological services are very important to reducing the level of psychological burnout and improves communication skills between members of families.

Study by Evolahti et al. (2013) purpose to determine the development of psychological burnout among women working in middle-aged, and to assess the relationship between work and psychological burnout. The study took 
a follow-up approach for 9 years. Sample of the study was 142 women. The tool for this study was using the Shirom-Melamed Burnout Questionnaire. In order to identify typical developmental patterns (trajectories) hierarchical cluster analysis was used, the statistical analysis of variance (ANOVA) showed no significant changes in burnout over time. However, underlying these levels, six trajectories were identified. These clusters represented four different developmental patterns: high levels followed by recovery, increasing levels, increasing and diminishing levels, and stable levels. Findings showed that the development of burnout was accompanied by concurrent changes in life stress as well as work-related and individual factors.

Research about psychological burnout has been studied by Blom (2012) the sample of the study included 2121 men and women workers, a regression analysis was used, the aim of the study was to examine the burnout also taking into consider work- and private life stressors. The results showed performance-based self-esteem mediated partially between the stresses and burnout. Performance-based self-esteem was the strongest predictor of burnout over time, followed by private life stresses. Women experienced more work stress than did men. The results also showed that psychological stress in men is a source of psychological burnout, while the women suffered from the relationship between self-esteem and psychological burnout, this shows Individual characteristics along with both private life and work stresses are important predictors of burnout with different psychological burnout factors in both men and women.

\section{Results}

First question: What are the risk factors of psychological burnout on a sample of women at menopause in Amman?

To answer this question, the arithmetic mean, standard deviations and the degree of psychological burnout factors were extracted on a sample of women. The Table 1 shows these results:

Table 1. The mathematical averages, standard deviations and the degree of psychological burnout factors on a sample of women are arranged in descending order

\begin{tabular}{cclccc}
\hline Rank & Number & \multicolumn{1}{c}{ Paragraph } & averages & $\begin{array}{c}\text { standard } \\
\text { deviation }\end{array}$ & $\begin{array}{c}\text { Burnout } \\
\text { level }\end{array}$ \\
\hline 1 & 4 & I feel pain in my body when the work accumulates & 4.41 & .623 & High \\
2 & 8 & I am not motivated to do new business & 3.05 & 1.466 & Medium \\
3 & 11 & I have a desire to escape & 3.02 & 1.512 & Medium \\
4 & 7 & I am constantly criticized for any mistake I make & 3.00 & 1.485 & Medium \\
5 & 14 & I do not want to compliment others & 2.96 & 1.564 & Medium \\
6 & 3 & I think that the tasks I do are of no importance & 2.94 & 1.577 & Medium \\
7 & 17 & I do not feel like wanting social posts & 2.94 & 1.470 & Medium \\
8 & 9 & Others ask me to do more than my energy & 2.93 & 1.500 & Medium \\
9 & 13 & I suffer from frequent complaint & 2.92 & 1.462 & Medium \\
10 & 10 & I do not find value for the work I do & 2.91 & 1.572 & Medium \\
11 & 6 & What I do is repeated daily to no avail & 2.90 & 1.535 & Medium \\
12 & 2 & I want to stop doing a lot of the work required of me & 2.89 & 1.538 & Medium \\
13 & 12 & The idea is that I will never rest & 2.89 & 1.491 & Medium \\
14 & 19 & I cannot bear more pressure & 2.89 & 1.564 & Medium \\
15 & 16 & I feel that my energy has been carried out & 2.88 & 1.486 & Medium \\
16 & 5 & I do not find the appropriate appreciation for my efforts & 2.87 & 1.397 & Medium \\
17 & 15 & I am not satisfied with the work I do & 2.80 & 1.512 & Medium \\
18 & 20 & Many businesses lost their meaning & 2.76 & 1.519 & Medium \\
19 & 1 & I feel tired and I cannot complete the work & 2.73 & 1.406 & Medium \\
20 & 18 & I want more rest & 2.69 & 1.523 & Medium \\
& & The total average of the psychological burnout scale & 2.97 & & 1.254 \\
\hline
\end{tabular}

Table 1 shows that the degree of psychological burnout of the total score of the psychological burnout scale on a sample of women reached (2.97) and the degree of psychological burnout medium, while the averages ranged between paragraphs (2.69 and 4.41) and came at medium and high levels, (I feel pain in my body when accumulating on the works) the first rank with the highest mean (4.41) and the degree of high psychological burnout. While the paragraph (I want more rest) came in last with the lowest average (2.69) and medium psychological burnout. 
Second question: What is the degree of psychological burnout of a sample of working women and housewives?

In order to answer this question, the mean and standard deviations and the $\mathrm{T}$ test were obtained for independent samples the level of psychological burnout on a sample of working and housewives women. Table 2 shows these results:

Table 2. Mean averages, standard deviations and the degree of psychological burnout factors on a sample of working and non-working women

\begin{tabular}{|c|c|c|c|c|c|c|}
\hline \multirow[b]{2}{*}{ Paragraph } & \multicolumn{3}{|c|}{ Working women } & \multicolumn{3}{|c|}{ Non-working women } \\
\hline & averages & $\begin{array}{l}\text { standard } \\
\text { deviation }\end{array}$ & $\begin{array}{c}\text { Burnout } \\
\text { level }\end{array}$ & averages & $\begin{array}{l}\text { standard } \\
\text { deviation }\end{array}$ & $\begin{array}{c}\text { Burnout } \\
\text { level }\end{array}$ \\
\hline I feel tired and I cannot complete the work & 1.53 & .649 & Low & 3.90 & .839 & High \\
\hline $\begin{array}{l}\text { I want to stop doing a lot of the work required of } \\
\text { me }\end{array}$ & 1.51 & 649 & Low & 4.24 & .744 & High \\
\hline I think that the tasks I do are of no importance & 1.53 & .616 & Low & 4.32 & .819 & High \\
\hline I feel pain in my body when the work accumulates & 4.39 & .640 & High & 4.44 & .611 & High \\
\hline $\begin{array}{l}\text { I do not find the appropriate appreciation for my } \\
\text { efforts }\end{array}$ & 1.69 & .742 & Low & 4.02 & .795 & High \\
\hline What I do is repeated daily to no avail & 1.61 & .759 & Low & 4.16 & .934 & High \\
\hline I am constantly criticized for any mistake I make & 1.71 & 677 & Low & 4.26 & .828 & High \\
\hline I am not motivated to do new business & 1.84 & .965 & Low & 4.24 & .687 & High \\
\hline Others ask me to do more than my energy & 1.63 & .727 & Low & 4.20 & .808 & High \\
\hline I do not find value for the work I do & 1.57 & .736 & Low & 4.22 & .932 & High \\
\hline I have a desire to escape & 1.80 & .866 & Low & 4.22 & .932 & High \\
\hline The idea is that I will never rest & 1.59 & .788 & Low & 4.16 & .710 & High \\
\hline I suffer from frequent complaint & 1.71 & .913 & Low & & .763 & High \\
\hline For the desire I have to compliment others & 1.63 & .883 & Low & 4.26 & .803 & High \\
\hline I am not satisfied with the work I do & 1.47 & .739 & Low & 4.10 & .735 & High \\
\hline I feel that my energy has been carried out & 1.51 & 617 & Low & 4.22 & .582 & High \\
\hline I do not feel like wanting social posts & 1.65 & .779 & Low & 4.20 & 670 & High \\
\hline I want more rest & 1.31 & .466 & Low & 4.04 & .807 & High \\
\hline I cannot bear more pressure & 1.47 & .544 & Low & 4.28 & .784 & High \\
\hline Many works lost their meaning & 1.39 & .533 & Low & 4.10 & .789 & High \\
\hline The total mean of psychological burnout & 1.73 & .155 & Low & 4.18 & .275 & High \\
\hline
\end{tabular}

Table 2 shows that the degree of psychological burnout of the total score of the psychological burnout scale on a sample of working women reached (1.73) and the degree of psychological burnout is low, while the averages of the paragraphs ranged between (1.31 and 4.39) and came at low and high levels, Paragraph (I feel pain in my body when accumulating on the works) the first grade with the highest mean (4.39) and the degree of high psychological burnout. While the paragraph (I want more rest) came last with the lowest mean (1.31) and a low level of psychological burnout.

The table shows that the total degree of psychological burnout on a sample of housewives women was (4.18) and the degree of psychological burnout is high, while the averages for the paragraphs ranged between ( 3.90 and 4.44) and came at low and high levels, I feel pain in my body when I am accumulating the works (first grade with the highest mean (4.44) and high psychological burnout. While the paragraph (I feel tired and unable to complete the work) came in last with the lowest average account (3.90) and high degree of psychological burnout.

Third question: What is the difference between the level of psychological burnout on a sample of working women and Housewives?

To answer this question, the mean and standard deviations and the $\mathrm{T}$ test were obtained for independent samples of the level of psychological burnout on a sample of working women and housewives. The following table shows these results.

Table 3 shows that the value of "T" for the independent samples of the psychological burnout scale is $(54,608)$, which is the value of a statistical function at the level of significance $(0.05)$, this indicates that there are 
significant differences in psychological burnout in a sample of working women and Housewives. The differences were in favor of working women. In other words, the level of psychological burnout among Housewives was higher than that of working women.

Table 3. Average and standard deviations and $\mathrm{T}$ test for independent samples on the psychological scale of a sample of working women and Housewives

\begin{tabular}{cccccccc}
\hline scale & status & number & average & $\begin{array}{c}\text { standard } \\
\text { deviation }\end{array}$ & $\begin{array}{c}\text { Value of } \\
\text { "T" }\end{array}$ & $\begin{array}{c}\text { Degrees of } \\
\text { freedom }\end{array}$ & $\begin{array}{c}\text { Statistical } \\
\text { significance }\end{array}$ \\
\hline Psychological burnout & working women & 50 & 1.73 & .155 & -54.608 & 97 & .000 \\
Psychological burnout & Housewives & 50 & 4.18 & .275 & &. \\
\hline
\end{tabular}

\section{Discussion}

When reviewing the results of the first question, we find that the most dangerous factor for the occurrence of psychological burnout was linked to the physical state of health, "I feel pain in my body when the work accumulates" While the remaining indicators recorded an average level of psychological burnout, This is a logical result because women in menopausal stage suffer from physical pain that occurs as a result of hormonal changes, This confirms the role of the physical dimension on the psychological dimension, While the last risk factor was recorded "I want more rest" This indicates that women need not only rest but also need psychological support . In general, working women and housewives - of this study suffer from a medium level of burnout.

As for the results of the second question There are low degrees of psychological burnout and this concerns working women, and high grades for housewives, This is contrary to what is common knowledge that working women are more vulnerable to psychological burnout as a result of the state of effort in their works and jobs, This is due to the state of empowerment that work and job, In addition to what the work of women achieve financial independence. Housewives suffer from a high level of psychological burnout, and this may be due to efforts in domestic work and carry them from the routine of boring and not get the financial return of those works.

For the study population "Jordan", official statistics indicate a decline in the participation of women in the labor market, this means that the majority of women do not work or housewives, based on the results of this study, the majority of women are vulnerable to burnout because they do not work, this constitutes a high risk factor for the mental health of women and the consequent disturbance of women's social and family roles.

Finally, the results of the third question, Statistical analysis showed that levels of psychological burnout were higher among housewives than the working women, this may be an indication of the positive role that leads to the work of women's lives, also work is often associated with an advanced scientific level, which indicates a higher level of experience and self-awareness, which helps women working with managing and solving their problems. While housewives suffer from the poor life experience because of a long stay at home and engage in routine household chores, this is reflected negatively on feelings of Self-esteem, this explains the suffering of housewives from psychological burnout. This study was similar to a study of Ahmad and Kahan (2018) on the similarity of the health and physical status of working women and housewives is same, and there are no differences in their health status.

This study differed with a study Lebert-Charron et al. (2018) which focused on the role of motherhood and its impact on working women, which leads to their suffering from psychological burnout because of the overlap of social roles while the current study did not distinguish between the social status of working women, their level of psychological burnout is low.

As for the study carried out by Dibaji et al. (2017) the results of the study showed that there were no statistical differences between working women and housewives regarding the state of stress, and the problems with the pressure they suffer coupled with time pressures and multiple tasks this finding is contrary to what the current result has reached.

The results of the present study were similar to the results of a study Choudhary, \& Ahmad (2017) while the psychological status of working women is better than the psychological situation of housewives, especially on the stage of menopause.

Study by Gardazi et al. (2016) differ with the current study in terms that their sample is small and also have taken the qualitative research method, He studied the causes of psychological burnout of working mothers And the effect of some variables, The results of the study compared with the current study that women working within the same age group suffer from the similarity of the level of psychological pressure. 
The Kermane (2016) was similar to the current study in terms of the number of sample members But it differed with the method of research as it used the method of experimental research and the application of tribal and remote measurement, but it differed with the method of research as it used the method of experimental research and the application pre and post measurement The results of the study showed an increase in psychological burnout among working women versus housewives, which is contrary to the current study.

And for the nine-year follow-up study by Evolahti et al. (2013) She was similar in that she chose the study sample of working women in the middle age and differed from the current study in that it did not address the study of housewives, it was designed to track the state of psychological burnout over time.

In a study conducted by Bloom 2012, the sample of the study was large, and the sample included men in addition to women, which is different from the current study, the study focused on some factors related to psychological burnout.

For the study community in Jordan and the city of Amman, the work of women faces a state of admiration and satisfaction, this explains why women workers are not exposed to psychological burnout, in addition working women face special attention at the family and community. Such as they may get the support of husband and son, and may not require some social obligations because it is a working woman. In contrast, housewives demand many family and social tasks, as well as lack of financial and social empowerment. This explains their suffering from psychological burnout.

\section{What Distinguishes This Study}

Study the psychological status of women in menopause, which is an important stage for women in multiple roles, in addition to the health changes associated with the hormonal system, and the reflection on the psychological situation.

This study showed the role of affirmative action in the life of women in menopause, the work is a psychological support for women at this stage, which is felt by the decline of self-efficacy and social value, and thus form a social phenomenon with a psychological support.

\section{Conclusions}

- Increasing social awareness of the importance of women's work and showing the role of work in the mental health of women, which positively reflects on their role as wife and mother.

- Develop community-based programs aimed at helping and rehabilitating women for appropriate work.

- Provide psychological counseling services for women in general and housewives in particular.

- $\quad$ Provide health and psychological care services for women in menopause.

- Working to find vital activities and programs that contribute to helping and empowering housewives.

- Conduct research in future about the same subject, and select large samples within multiple regions In order to increase its ability to generalize the results

\section{References}

Ahmad, A., \& Khan, A. (2018). Quality of Life among Married Working Women and Housewives. Singaporean Journal of Social Science. Retrieved from https://www.researchgate.net/publication/326584124

Assaf, G. (2015). The contribution of Jordanian women to the labor market Reality and challenges. Publisher: National Center for Human Resources Development, Amman, Jordan.

Blom, V. (2012). Contingent self-esteem, stressors and burnout in working women and men. Work Journal, $43(2)$.

Choudhary, L., \& Ahmad, A. (2017). A Study of Psychological Well-Being among Housewives and Working Women of Mithil a Region, North Bihar, India. International Journal of Human Resource \& Industrial Research, 4(2), 8-15.

Delina, G., \& Prabhakara Raya, R. (2013). A study on Work-Life Balance in Working Women. IRACST-International Journal of Commerce, Business and Management, 2(5).

Dibaji, S. M., Abedi, M. R., \&Oreyazi, S. H. R. (2017). Occupation or Home: Comparison Housewives and Working Women in the Variables of Stress, Depression and Perception of Quantitative, Mental and Emotional Home Demands. Review of European Studies, 9(2), 268. https://doi.org/10.5539/res.v9n2p268

Evolahti, A., Hultell, D., \& Collins, A. (2013). Development of burnout in middle-aged working women: A 
longitudinal study. $J$ Womens Health (Larchmt), 22(1), 94-103. https://doi.org/10.1089/jwh.2012.3507

Gardazi, S., Mobeen, N., \& Ali Gardazi, S. (2016). Causes of Stress and Burnout among Working Mothers in Pakistan. The Qualitative Report, 21(5), 916-932. Retrieved from https://nsuworks.nova.edu/tqr/vol21/iss5/10

Kermane, M. (2016). A Psychological Study on Stress among Employed Women and Housewives and Its Management through Progressive Muscular Relaxation Technique (PMRT) and Mindfulness Breathing. Journal of Psychology \& Psychotherapy.

Lebert-Charron, A., Dorard, G., Boujut, E., \& Wendland, J. (2018). Maternal Burnout Syndrome: Contextual and Psychological Associated Factors. Front. Psychol. https://doi.org/10.3389/fpsyg.2018.00885

Molodi, A., Shayanmehr, E. K., \& Niri, F. G. (2015). The relationship between communication skills and marital burnout with marital commitment in working women and housewives. International Journal of Psychology and Behavioral Research, 4(3), 285-289. Retrieved from http://www.ijpbrjournal.com

Okulcz-kozaryn, A., \& Valente, D. R. (2017). Life Satisfaction of Career Women and Housewives. Springer Science+Business Media B.V. and the International Society for Quality-of-Life Studies (ISQOLS) 2017. https://doi.org/10.1007/s11482-017-9547-2

Salvagioni, D., Melanda, F., Mesas, A., Gonza'lez, A., Gabani, F., \& Andrade, S. (2017). Physical, psychological and occupational consequences of job burnout: A systematic review of prospective studies. https://doi.org/10.1371/journal.pone.0185781

Smadi, E. (2017). The Effect of Group Counseling on the Level of Depression and Anxiety in a Sample of Women in the Menopausal Stage in Jordan. Canadian Social Science, 13(2), 70-77.

Yazdkhasti, M., Simbar, M., Abdi, F. (2015). Empowerment and Coping Strategies in Menopause Women. Iran Red Crescent Med J., 17(3), e18944. https://doi.org/10.5812/ircmj.18944

\begin{tabular}{|c|c|c|c|c|c|c|}
\hline number & Paragraph & 1 & 2 & 3 & 4 & 5 \\
\hline 1 & I feel tired and I cannot complete the work & & & & & \\
\hline 2 & I want to stop doing a lot of the work required of me & & & & & \\
\hline 3 & I think that the tasks I do not importance & & & & & \\
\hline 4 & I feel pain in my body when the work accumulates & & & & & \\
\hline 5 & I do not find the appropriate appreciation for my efforts & & & & & \\
\hline 6 & What I do is repeated daily to no avail & & & & & \\
\hline 7 & I am constantly criticized for any mistake I make & & & & & \\
\hline 8 & I am not motivated to do new business & & & & & \\
\hline 9 & Others ask me to do more than my energy & & & & & \\
\hline 10 & I do not find value for the work I do & & & & & \\
\hline 11 & I have a desire to escape & & & & & \\
\hline 12 & The idea is that I will never rest & & & & & \\
\hline 13 & I suffer from frequent complaint & & & & & \\
\hline 14 & I do not want to compliment others & & & & & \\
\hline 15 & I am not satisfied with the work I do & & & & & \\
\hline 16 & I feel that my energy has been carried out & & & & & \\
\hline 17 & I do not feel like wanting social posts & & & & & \\
\hline 18 & I want more rest & & & & & \\
\hline 19 & I cannot bear more pressure & & & & & \\
\hline 20 & Many works lost their meaning & & & & & \\
\hline
\end{tabular}

\section{Copyrights}

Copyright for this article is retained by the author(s), with first publication rights granted to the journal.

This is an open-access article distributed under the terms and conditions of the Creative Commons Attribution license (http://creativecommons.org/licenses/by/4.0/). 